Кириллина Юлия Владимировна

кандидат экономических наук, доцент, доцент кафедры практической

и прикладной информатики

МИРЭА - Российского

технологического университета

Кириллина Лидия Сергеевна

студент кафедры бизнес-технологий и управления МИРЭА - Российского

технологического университета

\section{ВНЕДРЕНИЕ ТЕХНОЛОГИИ КОНТРОЛЛИНГА ЗАКУПОК В МАЛОЙ СТРОИТЕЛЬНОЙ КОМПАНИИ КАК СПОСОБ ПОВЫШЕНИЯ ЭФФЕКТИВНОСТИ ДЕЯТЕЛЬНОСТИ}

\section{Аннотация:}

В статье рассматриваются вопросы внедрения технологии контроллинга закупок в организации малого бизнеса, ведущие хозяйственную деятельность в отрасли строительства, с целью обеспечения экономии материальных затрат и повышения показателей рентабельности. Исследование ранее опубликованных работ по указанной проблематике выявило наличие постулата о необходимости организации контроллинга для повышения эффективности деятельности либо путем создания отдельных служб контроллинга, либо найма специалиста по контроллингу. Данное решение не подходит организациям малого бизнеса. Так, авторы предлагают внедрять данную технологию по объектам контроллинга и наделять соответствующими функциями сотрудников организации. Кроме того, в работе дано определение технологии контроллинга закупок, а также представлена модель бизнес-процесса, отражающая реализацию данной технологии.

Ключевые слова:

рентабельность, эффективность, экономия, отрасль строительства, контроллинг, закупка, технология контроллинга закупок, модель бизнеспроцесса.
Kirillina Yulia Vladimirovna

$\mathrm{PhD}$ in Economics Associate Professor Practical and Applied Computer Science Department MIREA - Russian Technological University

Kirillina Lidia Sergeyevna

Student, Business Technologies and Management Department, MIREA - Russian Technological University

\section{THE IMPLEMENTATION OF PURCHASING CONTROLLING TECHNOLOGY IN A SMALL CONSTRUCTION COMPANY AS A WAY TO IMPROVE PERFORMANCE}

The paper considers the implementation of purchasing controlling technology in a small business organization operating in the construction industry in order to save material costs and increase profitability. The study of previously published works on the subject has revealed the existence of a postulate about the need to organize controlling system to improve performance, either by creating separate controlling services or hiring a controlling specialist. This solution is not suitable for small business organizations, so the authors suggest implementing controlling technology in small construction companies for controlling objects and assigning appropriate functions to employees of the organization. The work defines the technology of controlling purchases, and also presents a business process model that reflects the implementation of this technology.

Keywords: profitability, efficiency, cost savings, construction industry, controlling, purchase, technology for controlling purchases, business process model.

Для любой коммерческой организации важным критерием является обеспечение эффективности деятельности, которая формируется за счет стабильных доходов (выручки и прибыли) и расходов (затрат на осуществление деятельности). При этом рост эффективности деятельности может быть обеспечен сокращением затрат организации даже при отсутствии роста или падения выручки (прибыли).

Отрасль строительства характеризуется высоким уровнем материалоемкости, поэтому вопрос снижения затрат организаций на осуществление основной деятельности в создавшихся экономических условиях является весьма актуальным. Достаточно посмотреть на среднеотраслевые показатели, характеризующие финансово-хозяйственную деятельность налогоплательщиков, представляемые ежегодно Федеральной налоговой службой РФ в рамках Концепции системы планирования выездных налоговых проверок [1]. Так, показатель рентабельности активов по виду экономической деятельности (ОКВЭД-2) «Строительство» в течение 2015-2019 гг. имеет отрицательную динамику, а показатель рентабельности проданных товаров (продукции, работ, услуг) за тот же период характеризуется нестабильной динамикой (таблица 1). 
Таблица 1 - Установленные значения рентабельности на 2015-2019 гг., \%

\begin{tabular}{|l|c|c|c|c|c|}
\hline Показатель & $\mathbf{2 0 1 5}$ г. & $\mathbf{2 0 1 6}$ г. & $\mathbf{2 0 1 7}$ г. & $\mathbf{2 0 1 8}$ г. & $\mathbf{2 0 1 9}$ г. \\
\hline Рентабельность проданных товаров & 5,4 & 5,5 & 7,2 & 6,1 & 7,0 \\
\hline Рентабельность активов & 1,9 & 1,9 & 1,8 & 1,7 & 1,5 \\
\hline
\end{tabular}

Принцип расчета данных показателей представлен в формулах 1, 2:

$$
R_{\text {пр.т }}=\frac{\text { стр. } 2200}{\text { стр. 2120+стр. 2210+стр. 2220 }}
$$

где $\quad R_{\text {пр.т }}-$ рентабельность проданных товаров (продукции, работ, услуг);

стр. 2200 - прибыль от продаж в Отчете о финансовых результатах;

стр. 2120 - себестоимость проданных товаров (работ, услуг) там же;

стр. 2210 - коммерческие расходы там же;

стр. 2220 - управленческие расходы там же.

$$
R_{\mathrm{a}}=\frac{\text { стр. } 2200}{\bar{A}},
$$

где $\quad R_{\mathrm{a}}$ - рентабельность активов;

стр. 2200 - прибыль от продаж;

$\bar{A}$ - среднегодовая стоимость актива бухгалтерского баланса.

Учитывая данный принцип расчета, можно сделать вывод о том, что колебание среднеотраслевой рентабельности проданных товаров (продукции, работ, услуг) вызвано либо отсутствием стабильного роста прибыли от продаж, либо отсутствием стабильного снижения расходов организаций, либо влиянием обоих фракторов. В свою очередь снижение среднеотраслевой рентабельности активов также может быть обусловлено отсутствием стабильного роста прибыли от продаж, увеличением стоимости активов или влиянием обоих фракторов. Соответственно, чтобы у строительной компании при условии отсутствия роста прибыли от продаж показатели были выше указанных среднеотраслевых величин, необходимо обеспечивать снижение затрат не с помощью однократного решения вопроса, а на постоянной основе, используя для этого технологию контроллинга закупок.

Как известно, контроллинг определяется как «философия и образ мышления руководителей, ориентированные на эффективное использование ресурсов и развитие предприятия в долгосрочной перспективе» [2, с. 44]. Наиболее значимыми основными постулатами философии контроллинга являются следующие:

- «приоритет рентабельности деятельности и роста стоимости предприятия в долгосрочной перспективе над ростом объемных показателей» [3, с. 44];

- «мероприятия по обеспечению роста эффрективности и стоимости предприятия не должны превышать допустимые для конкретных условий функционирования уровни рисков» [4, с. 45].

Вследствие этого рентабельность проданных товаров (продуктов, работ, услуг) и рентабельность активов, являясь относительными показателями эффективности деятельности, выступают как индикаторы эфффективности принимаемых решений в целом по организации.

Применительно к отрасли строительства вопросы повышения эффективности деятельности организаций на основе внедрения контроллинга (в том числе оперативного контроллинга), направленного на достижение необходимого уровня рентабельности и ликвидности организации, рассматривались неоднократно. Так, Т.Б. Юрьевой предлагается сначала реализовать в компании разработку аналитической информации, а затем разработать систему бюджетирования, что позволит «получить дополнительное конкурентное преимущество на строительном рынке за счет готовности работать в условиях строгой внутренней экономии» [5, с. 177]. Также автор рекомендует начинать с внедрения оперативного контроллинга [6, с. 28], реализация которого будет осуществляться через контроллинговый центр, выступающий как самостоятельная и независимая служба, подотчетная только высшему руководству [7, с. 29]. В статье Н.С. Нечеухиной и Н.А. Полозовой также констатируется, что «внедрение системы контроллинга в строительных холдингах позволяет повысить эффективность всего процесса управления его экономической деятельностью» [8, с. 29], и в качестве одного из этапов организации системы контроллинга предлагается создание структуры контроллинга, которая предполагает, в свою очередь, кадровое обеспечение. В работе Д.В. Суходоева, Т.В. Стожаровой, О.М. Гриневой выделяется несколько групп должностных лиц, которые осуществляют функцию контроллинга:

- собственники, которые осуществляют контроллинговую функцию с помощью независимых экспертов;

- администрация, имеющая функции управления и контроля; ностей;

- специалисты, которые занимаются контроллингом в рамках своих должностных обязан- 
- служащие, осуществляющие контроль качества результатов своего труда;

- контролеры, проводящие аудиторские проверки по решению администрации [9, с. 163].

Однако фринансовые возможности строительных холдингов и крупных компаний не могут сравниться с финансовыми возможностями малых предприятий, где чаще всего функции контроллера выполняет руководитель. С постепенным увеличением масштабов деятельности в небольшой организации возникает вопрос: каким образом организовать контроллинг, не нанимая специалистов для этих целей? Кроме того, не все служащие компании осуществляют или хотят осуществлять контроль качества результатов своего труда. Решение данной проблемы авторам статьи видится во внедрении технологии контроллинга в малой строительной организации по объектам контроллинга. Учитывая, что объектов контроллинга существует достаточно много (внешняя среда, маркетинг, производство, логистика и т. д.), в рамках данной статьи рассматривается только внедрение технологии контроллинга закупок путем изменения существующей модели бизнес-процесса в организации с целью снижения затрат на обеспечение компании ресурсами в процессе строительно-монтажных работ и повышения показателей рентабельности.

Дальнейшее использование термина «технология контроллинга закупок» требует рассмотрения ряда взаимосвязанных в нем понятий: закупка, контроллинг закупок и технология. Закупка может быть определена как процесс приобретения товаров (работ, услуг), состоящий из нескольких подпроцессов:

- выявление потребности в товаре (работе, услугах);

- поиск и выбор поставщика;

- заключение и исполнение договора о поставке товара (выполнения работ, оказания услуг).

Контроллинг закупок (обеспечения закупок) направлен:

- на контроль за экономичностью издержек при снабжении материалами;

- текущую оценку закупок;

- формирование системы материального снабжения, ориентированной на рынок [10, с. 88].

В соответствии с этим, экономичность издержек при снабжении материалами оказывает прямое влияние на уровень показателей рентабельности: обеспечивая рост экономии в расходах, обеспечивается увеличение рентабельности даже при сохранении уровня доходов компании.

Реализация контроллинга закупок в организации должна быть сориентирована на то, чтобы закупочная деятельность обеспечивала получение товаров, работ, услуг определенного качества в необходимом количестве в требуемое время и по минимальной цене. Применительно к строительной организации это означает поставку необходимого количества и качества строительных материалов в нужное время по минимальной цене с целью обеспечения непрерывности строительных работ. Одним из инструментов контроллинга закупок является исследование рынков закупаемых товаров и анализ поставщиков, которые предполагают сбор внутренней и внешней информации, ее обработку, систематизацию, классификацию, анализ, хранение для дальнейшего использования. При этом особое внимание уделяется качеству, количеству и ценам товаров у разных поставщиков, их месторасположению и срокам поставок.

В экономическом словаре технология определена как «способ преобразования вещества, энергии, информации в процессе изготовления продукции, обработки и переработки материалов, сборки готовых изделий, контроля качества, управления. Технология воплощает в себе методы, приемы, режим работы, последовательность операций и процедур, она тесно связана с применяемыми средствами, оборудованием, инструментами, используемыми материалами» [11]. Исходя из этого, можно определить технологию контроллинга закупок как последовательность операций по обработке инфрормации и принятию решений при осуществлении закупок с целью обеспечения экономичности издержек (данное определение является авторским и не имеет аналогов в отечественных исследованиях).

В данной статье была рассмотрена деятельность строительной компании ООО «МигПлюс». Потребность во внедрении технологии контроллинга закупок у данной организации возникла по объективным причинам, которые будут представлены далее.

Компания ООО «Миг-Плюс» осуществляет основной вид деятельности по ОКВЭД: 43.22 Работы строительные специализированные. Производство санитарно-технических работ, монтаж отопительных систем и систем кондиционирования воздуха.

Данная группировка включает:

- монтаж водопроводных систем, систем отопления и кондиционирования воздуха, включая их реконструкцию, обслуживание и ремонт;

- установку (монтаж) в зданиях или сооружениях отопительных систем (электрических, газовых и масляных), печей и каминов, стояков водяного охлаждения, неэлектрических коллекторов солнечной энергии, водопроводного и сантехнического оборудования, оборудования вентиляции и 
кондиционирования воздуха и воздуховодов, газопроводной арматуры, трубопроводов для подачи пара, систем автоматического пожаротушения, автоматических систем для полива газонов;

- работу по монтажу трубопроводов [12].

Выбор компании ООО «Миг-Плюс» как модельной организации для внедрения технологии контроллинга закупок обусловлен следующими причинами:

- длительная история деятельности компании в сфере строительного бизнеса (около 20 лет);

- положительные экономические результаты деятельности на фоне ухудшения показателей конкурентов;

- важность деятельности компании в условиях реализации государственной программы РФ «Энергосбережение и повышение энергетической эфффективности на период до 2020 г.».

Объективными причинами необходимости внедрения технологии контроллинга закупок стало снижение показателей рентабельности проданных товаров и активов организации в 20172019 гг. (таблица 2).

Таблица 2 - Показатели рентабельности ООО «Миг-Плюс» за 2017-2019 гг., \%

\begin{tabular}{|l|c|c|c|}
\hline \multicolumn{1}{|c|}{ Показатель } & $\mathbf{2 0 1 7}$ r. & $\mathbf{2 0 1 8}$ г. & $\mathbf{2 0 1 9}$ г. \\
\hline Рентабельность проданных товаров & 18,3 & 11,3 & 8,0 \\
\hline Рентабельность активов & 31,6 & 18,5 & 14,1 \\
\hline
\end{tabular}

При этом фрактическая величина значений показателей рентабельности выше среднеотраслевых показателей, характеризующих финансово-хозяйственную деятельность налогоплательщиков, представленных ранее.

Одной из причин снижения показателя рентабельности проданных товаров явился стабильный рост затрат организации по таким направлениям, как расходы на оплату труда и отчисления на социальные нужды, а также нестабильное изменение материальных затрат (таблица 3).

Таблица 3 - Горизонтальный анализ затрат, в тыс. руб.

\begin{tabular}{|c|c|c|c|c|c|c|c|}
\hline \multirow{2}{*}{$\begin{array}{c}\text { Наименование } \\
\text { показателя }\end{array}$} & \multirow{2}{*}{2017 г. } & \multirow{2}{*}{2018 г. } & \multirow{2}{*}{2019 г. } & \multicolumn{2}{|c|}{$\begin{array}{c}\text { Абсолютное } \\
\text { изменение, в тыс. руб. }\end{array}$} & \multicolumn{2}{|c|}{$\begin{array}{l}\text { Относительное } \\
\text { изменение, в \% }\end{array}$} \\
\hline & & & & $\begin{array}{l}2018 \text { г. } \\
\text { к } 2017 \text { г. }\end{array}$ & $\begin{array}{c}2019 \text { г. } \\
\text { к } 2018 \text { г. }\end{array}$ & $\begin{aligned} 2018 \text { г. } \\
\text { к } 2017 \text { г. }\end{aligned}$ & $\begin{array}{l}2019 \text { г. } \\
\text { к } 2018 \text { г. }\end{array}$ \\
\hline Материальные затраты & 31912 & 38518 & 35491 & 6605 & -3027 & 120,7 & 92,1 \\
\hline $\begin{array}{l}\text { Расходы на оплату } \\
\text { труда }\end{array}$ & 32351 & 42241 & 49006 & 9890 & 6765 & 130,6 & 116,0 \\
\hline $\begin{array}{l}\text { Отчисления } \\
\text { на социальные нужды }\end{array}$ & 9506 & 12571 & 15526 & 3064 & 2955 & 132,2 & 123,5 \\
\hline Амортизация & 2302 & 2384 & 2151 & 82 & -233 & 103,6 & 90,2 \\
\hline Прочие затраты & 34294 & 30147 & 30454 & -7034 & 307 & 79,5 & 101,0 \\
\hline Итого по элементам & 110365 & 125861 & 132628 & 12608 & 6767 & 111,4 & 105,4 \\
\hline
\end{tabular}

Вертикальный анализ затрат позволил сделать выводы о структуре затрат на производство в организации (таблица 4). Деятельность компании характеризуется как зарплатоемкая. В то же время удельный вес материальных затрат за трехлетний период то увеличивался, то снижался в структуре затрат.

Таблица 4 - Вертикальный анализ затрат за 2017-2019 гг.

\begin{tabular}{|l|c|c|c|c|c|c|}
\hline Наименование показателя & \multicolumn{2}{|c|}{$\mathbf{2 0 1 7}$ г. } & \multicolumn{2}{|c|}{$\mathbf{2 0 1 8}$ г. } & \multicolumn{2}{c|}{ 2019 г. } \\
\hline & Тыс. руб. & $\begin{array}{c}\text { Удельный } \\
\text { вес, \% }\end{array}$ & Тыс. руб. & $\begin{array}{c}\text { Удельный } \\
\text { вес, \% }\end{array}$ & Тыс. руб. & $\begin{array}{c}\text { Удельный } \\
\text { вес, \% }\end{array}$ \\
\hline Материальные затраты & 31912 & 28,9 & 38518 & 30,6 & 35491 & 26,8 \\
\hline Расходы на оплату труда & 32351 & 29,3 & 42241 & 33,6 & 49006 & 36,9 \\
\hline $\begin{array}{l}\text { Отчисления на социальные } \\
\text { нужды }\end{array}$ & 9506 & 8,6 & 12571 & 10,0 & 15526 & 11,7 \\
\hline Амортизация & 2302 & 2,1 & 2384 & 1,9 & 2151 & 1,6 \\
\hline Прочие затраты & 34294 & 31,1 & 30147 & 24,0 & 30454 & 23,0 \\
\hline Итого по элементам & 110365 & 100 & 125861 & 100 & 132628 & 100 \\
\hline
\end{tabular}

В начале статьи было указано, что сфера деятельности строительных компаний характеризуется как материалоемкая. В данной конкретной организации наблюдается зарплатоемкость, что связано со специализацией вида деятельности. Компания специализируется на строительстве блочных и модульных котельных на газе или дизеле. Создание такого рода объектов осуществляется на собственной производственной площадке, а затем готовый объект, состоящий 
из крупных модулей, транспортируется на площадку для установки. Окончательная сборка котельной проходит на подготовленной площадке заказчика.

Для данной компании стала актуальной работа над материальными затратами в связи с их увеличением. Причиной роста, а также превышения фактических значений над плановыми явилась закупка материалов и оборудования без анализа предложений других поставщиков, а также приобретение материалов и оборудования, не соответствующих смете (спецификации).

В организации фрактический учет по осуществлению строительно-монтажных работ, связанных со строительством газовых и дизельных котельных, осуществляет производственно-технический отдел, который по каждому возводимому объекту ведет специальный контрольный отчет. Данный специальный контрольный отчет содержит в себе:

1. Укрупненную информацию по сметным значениям строящегося объекта.

2. Информацию о фактических затратах, включая затраты на основное оборудование (котлы, горелки, насосы и т. п.), запорную арматуру (краны, клапаны, тройники и т. п.), трубопроводы (трубы различного диаметра, заглушки, отводы и т. п.), приборы КИПиА и прочее.

Специальный контрольный отчет ведется в течение всего периода строительства и закрывается по фракту сдачи объекта в эксплуатацию, что позволяет вести учет нарастающим итогом и впоследствии выявлять отрицательные и благоприятные отклонения. Также в отчете фиксируется фракт затрат, что предполагает осуществление управленческих мероприятий, которые не позволят привести к необоснованному росту расходов в дальнейшем. Однако сотрудники производственно-технического отдела не обладают такой возможностью. Кроме того, целесообразнее не допускать рост затрат до их возникновения, чем пытаться нивелировать рост затрат, которые были уже осуществлены.

В настоящее время закупку материалов и оборудования для осуществления строительномонтажных работ осуществляет сотрудник, напрямую подчиняющийся руководителю монтажного отдела, путем формирования заявки на закупку и подписания ее у руководителя монтажного отдела. Впоследствии утвержденная заявка становится основанием для оплаты выставленного поставщиком счета. Данная организация процесса закупки не предполагает ответственности ни со стороны сотрудника, осуществляющего закупку, ни со стороны руководителя монтажного отдела. Контрольные мероприятия по обоснованности закупаемого материала и оборудования у конкретного поставщика отсутствуют. На рисунках 1-3 представлена существующая модель бизнес-процесса, включающая в себя два подпроцесса: «Обработать информацию» и «Подготовить документы в бухгалтерию». Каждый подпроцесс отдельно декомпозируется.

Так как компания относится к малому бизнесу с численностью до 100 человек, то введение должности контроллера в штатное расписание не рассматривается. Выходом из такой ситуации, по мнению авторов, может быть как раз внедрение технологии контроллинга закупок путем изменения существующей модели бизнес-процесса. Реализовать технологию контроллинга закупок могут руководитель отдела продаж и финансовый директор. Руководитель отдела продаж, отвечающий за формирование коммерческих предложений потенциальным заказчикам, а также за заключение договоров строительства объектов, обладает информацией о требуемом для строительно-монтажных работ (СМР) оборудовании: котлы, горелки и прочее. Финансовый директор организации отвечает за фринансовые потоки в организации, за расходы и доходы. Так как закупка материалов и оборудования в рамках СМР является затратной статьей в рамках хозяйственной деятельности, то контрольные мероприятия по обоснованности закупок также могут находиться в зоне его ответственности.

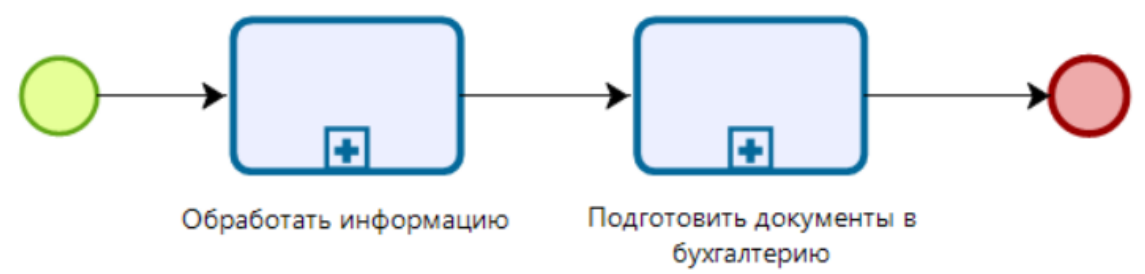

Рисунок 1 - Существующая модель бизнес-процесса осуществления закупок 


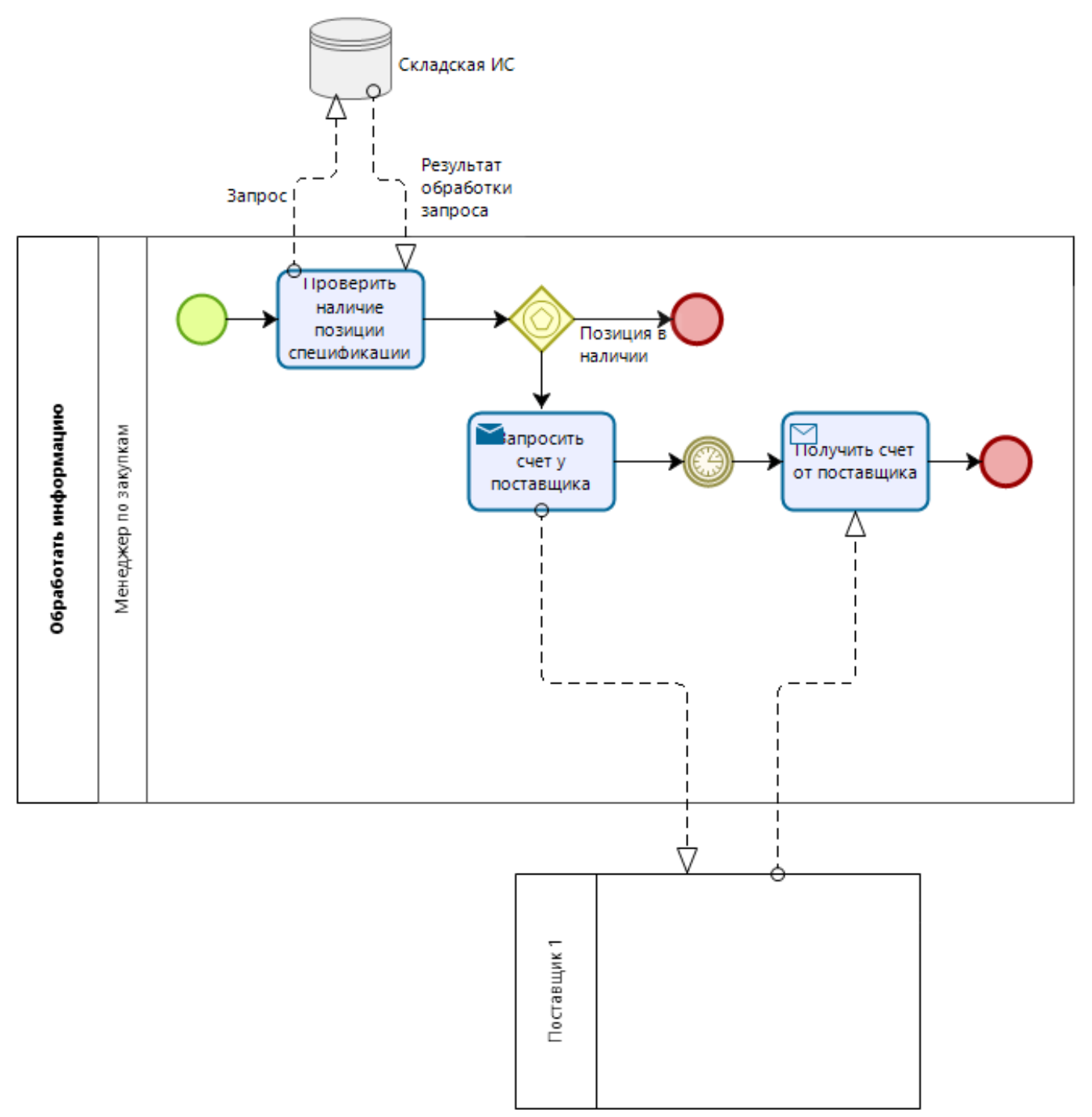

Рисунок 2 - Существующая модель подпроцесса «Обработать информацию»

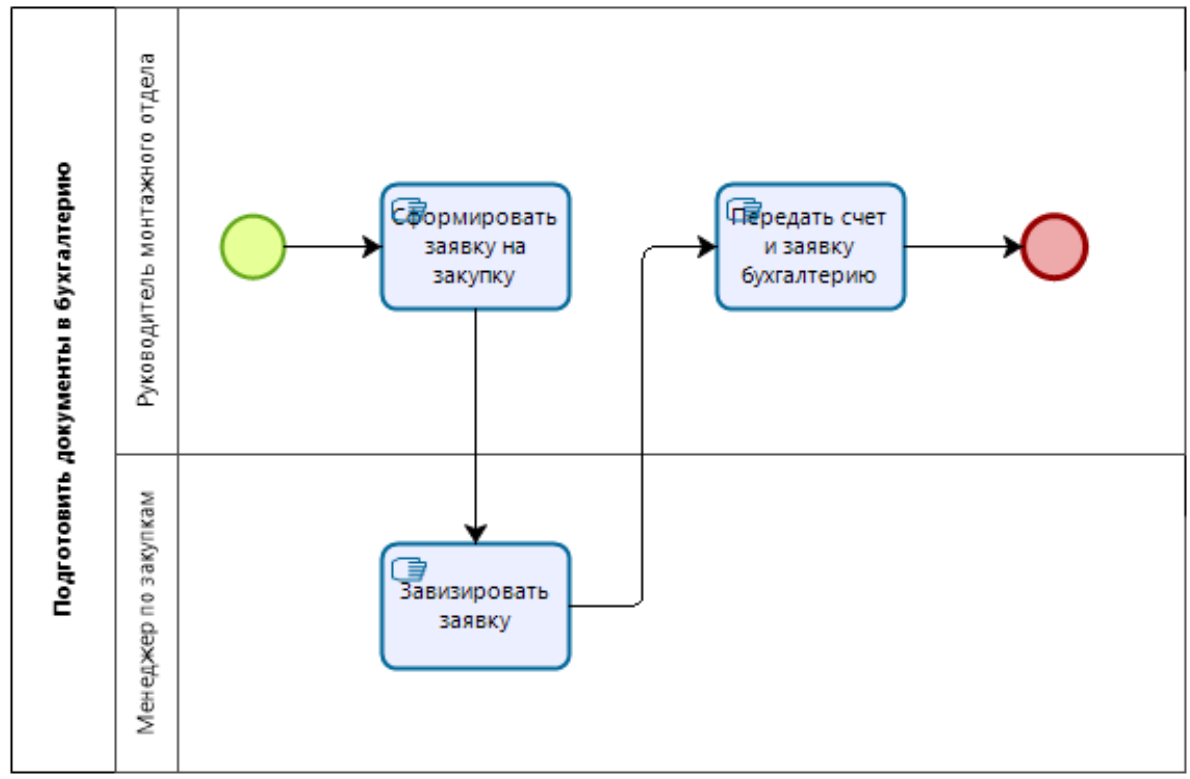

Рисунок 3 - Существующая модель подпроцесса «Подготовить документы в бухгалтерию» 
Реализацию технологии контроллинга закупок можно представить в виде модели бизнеспроцесса, в котором будут участвовать менеджер по закупкам, руководитель отдела продаж, фринансовый директор, руководитель монтажного отдела. В качестве информационных ресурсов будут выступать складская информационная система, база данных поставщиков, Интернет. Инструментом контроллинга закупок будет исследование рынка поставщиков на основе внутренней и внешней информации. В качестве документов для анализа выступают счета от поставщиков. Результатом обработки счетов от поставщиков является аналитическая фрорма (АФ) сравнения цен по позициям с выбором по минимальной цене при условии требуемых сроков поставки.

Новая модель бизнес-процесса представлена на рисунке 4, где функции «Обработать информацию», «Осуществить контроллинг закупок», «Подготовить документы в бухгалтерию» являются вложенными процессами.

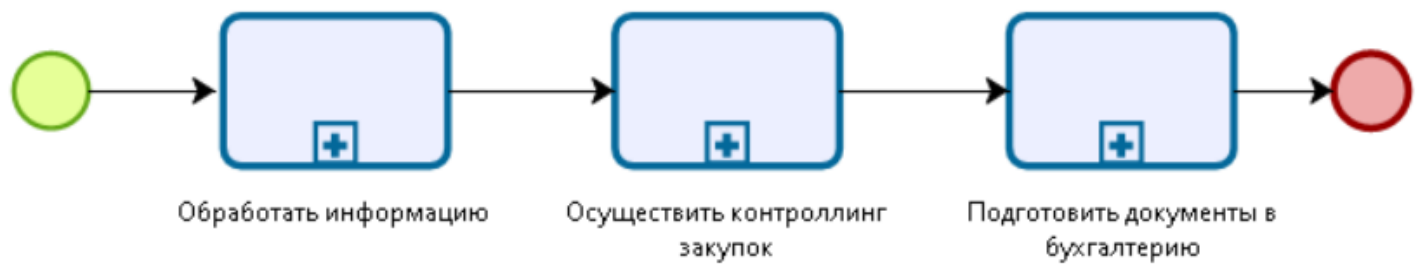

Рисунок 4 - Новая модель бизнес-процесса

На рисунке 5 представлен подпроцесс «Обработать информацию». Данный подпроцесс реализуется менеджером по закупкам и состоит из функций, предназначенных для проверки наличия необходимых для СМР по конкретному объекту строительства позиций на складе. В случае, если необходимая позиция не обнаружена, запускается подпроцесс «Подобрать поставщика», в рамках которого менеджер, используя информацию внешнюю и внутреннюю, подбирает поставщиков, которые могут осуществить поставку нужной позиции. По каждой позиции для осуществления сравнения цен требуется не менее двух поставщиков. После подбора поставщиков необходимо запросить счет на необходимую позицию, дождаться получения и сформировать аналитическую форму.

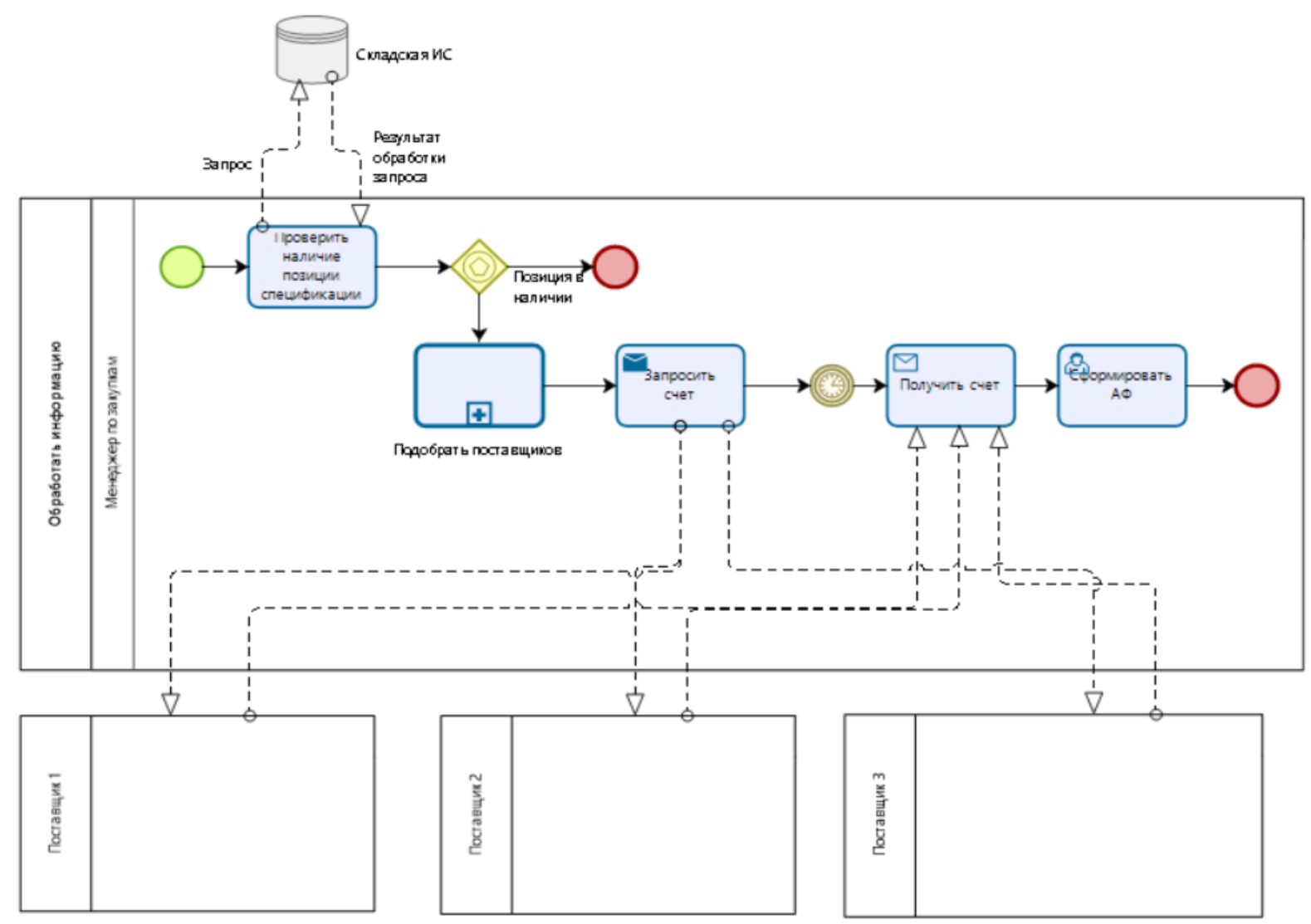

Рисунок 5 - Модель подпроцесса «Обработать информацию» (новый вариант) 
На рисунке 6 представлен подпроцесс «Осуществить контроллинг закупок».

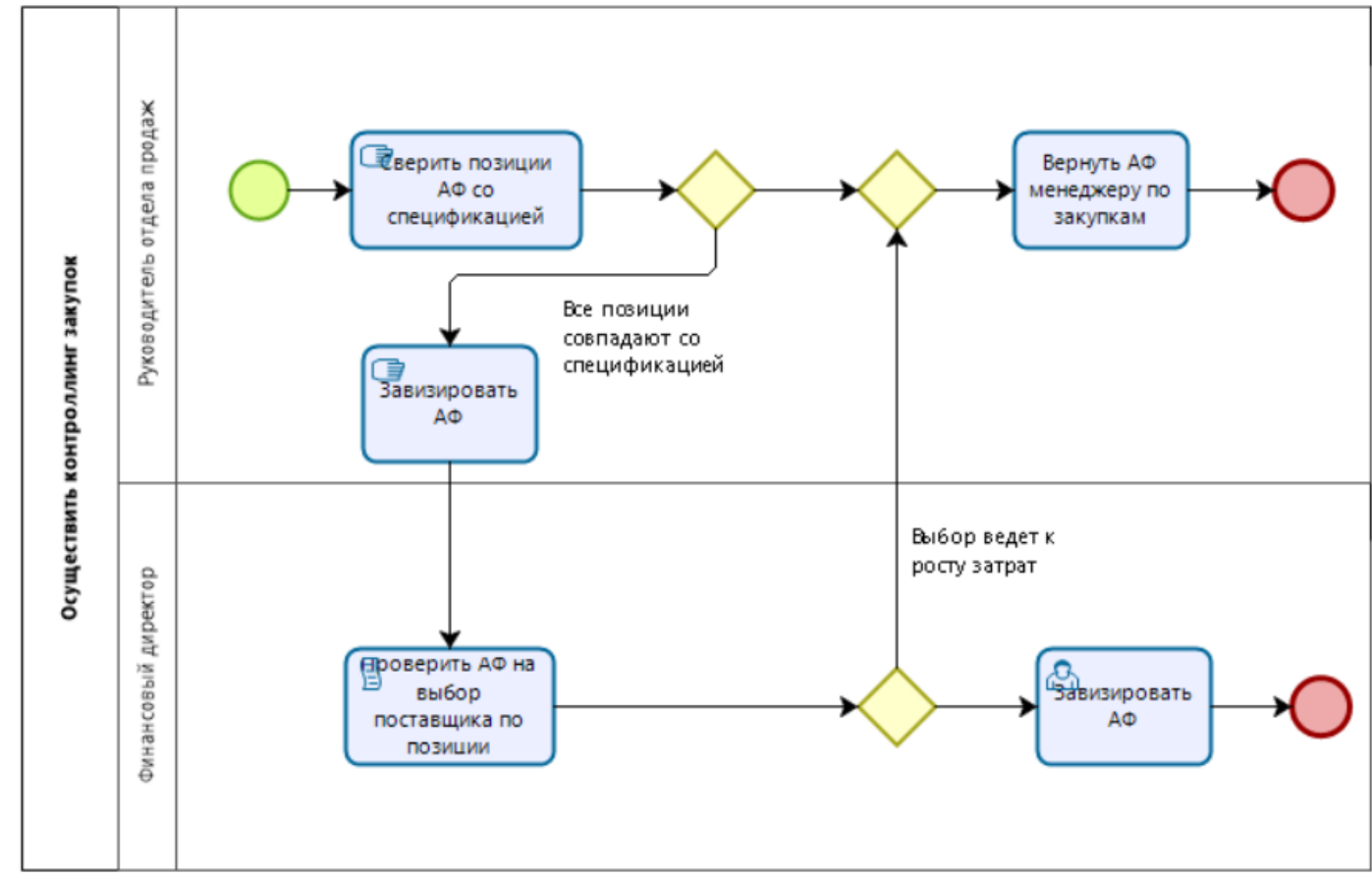

Рисунок 6 - Модель подпроцесса «Осуществить контроллинг закупок» (новый вариант)

В контроллинге закупок будут участвовать руководитель отдела продаж и финансовый директор. При этом каждый выполняет свои функции последовательно. Руководитель отдела продаж сверяет позиции, указанные в аналитической форме с тем, что было изначально указано в спецификации (смете) по объекту строительства. Финансовый директор проверяет правильность выбора со стороны менеджера. Основная цель проверки - не допустить незапланированного роста затрат на закупку по сравнению с тем, что было запланировано. Подпроцесс «Осуществить контроллинг закупок» считается положительно завершенным после визирования аналитической формы обоими сотрудниками компании. В случае возврата аналитической формы ее корректировка будет осуществляться менеджером по закупкам по альтернативному сценарию в зависимости от причины возврата.

На рисунке 7 представлен подпроцесс «Подготовить документы в бухгалтерию», в котором участвует менеджер по закупкам и руководитель монтажного отдела.

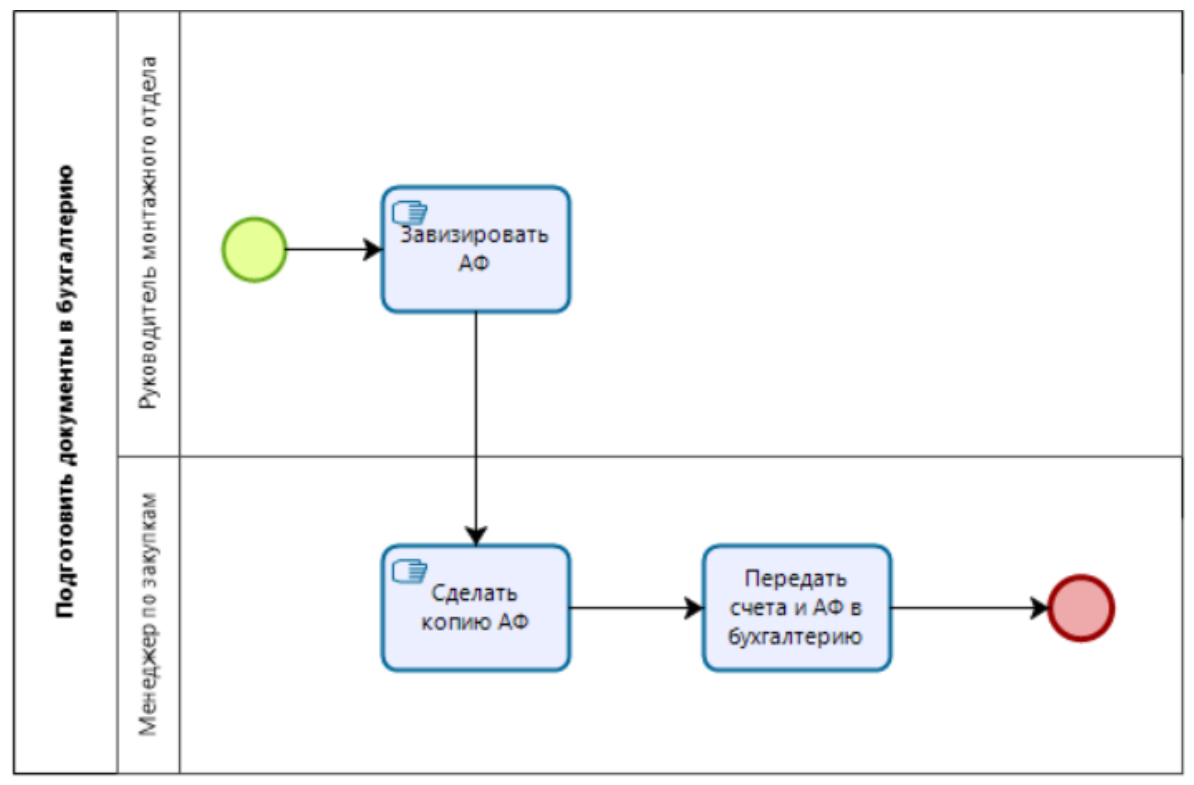

Рисунок 7 - Модель подпроцесса «Подготовить документы в бухгалтерию» (новый вариант) 
Предварительная оценка внедрения технологии контроллинга закупок в строительной компании, полученная на основе сравнительного анализа цен по материалам и оборудованию одного объекта строительства с последующей экстраполяцией на другие объекты строительства, показала возможность снижения затрат на материалы в размерах:

- 5,75\% по сравнению с запланированными на 2020 г. значениями затрат;

- 1,63\% по сравнению с фрактически осуществленными в 2019 г.;

- 4,49\% по сравнению с фрактически осуществленными в 2019 г. с поправкой на инфляцию.

Соответственно снижение затрат при отсутствии изменения других фракторов, оказывающих влияние на показатели рентабельности, позволяет рассчитывать на рост показателей рентабельности.

Таким образом, внедрение и последующая реализация технологии контроллинга закупок в строительной компании, относящейся к малому бизнесу и осуществляющей деятельность в сфрере специализированных строительных работ, позволяет:

1. Реализовать информационно-аналитическую функцию контроллинга по отношению к такому объекту, как закупка.

2. Не вводить в штатное расписание новую должность или формировать целый отдел и тем самым увеличивать затраты организации.

3. Устранить проблему нежелания ряда специалистов контролировать качество результатов своей работы.

4. Контролировать затраты, возникающие при приобретении материалов и оборудования.

5. Обеспечить снижение затрат при закупках материалов и оборудования по сравнению с запланированными значениями.

6. Обеспечить увеличение показателей рентабельности при отсутствии отрицательного изменения иных факторов влияния.

В заключение нужно отметить, что предложенная технология контроллинга закупок может использоваться малыми строительными организациями, аналогичными рассмотренному ООО «МигПлюс» по виду и масштабам деятельности, при решении возникающих проблем с сфере закупок.

\section{Ссылки:}

1. Концепция системы планирования выездных налоговых проверок [Электронный ресурс] // Официальный сайт Федеральной налоговой службы. URL: https://www.nalog.ru/rn77/taxation/reference work/conception vnp/ (дата обращения: 11.07.2020)

2. Фалько С.Г. Контроллинг для руководителей и специалистов. М., 2008. 272 с.

3. Там же. С. 44

4. Там же. С. 45

5. Юрьева Т.Б. Эффективность системы управления строительным предприятием на основе концепции контроллинга // Молодой ученый. 2011. № 6 (29). С. 176-177.

6. Юрьева Т.Б. Методические и организационные основы контроллинга в строительной деятельности // Учет и статистика. 2011. № 4 (24). С. 25-30.

7. Там же. С. 29

8. Нечеухина Н.С., Полозова Н.А. Контроллинг как инструмент эффрективного управления в строительных холдингах // Международный бухгалтерский учет. 2012. № 20 (218). С. 17-23.

9. Суходоев Д.В., Стожарова Т.В., Гринева О.М. Организационно-методические основы системы контроллинга // Символ науки. 2016. № 9. С. 162-164.

10. Карминский А.М., Жевага А.А., Иванова Н.Ю. Контроллинг : учебник / под ред. А.М. Карминского, С.Г. Фалько. $\mathrm{M}, 2009.336 \mathrm{c}$.

11. Экономический словарь [Электронный ресурс] // EkSlovar.Ru. URL: https://ekslovar.ru/t/tehnologiya (дата обращения: 11.05.2020).

12. Общероссийский классификатор видов экономической деятельности ОКВЭД-2 [Электронный ресурс] // БУХпрофи. URL: https://www.buxprofi.ru/spravochnik/okved-2 (дата обращения: 11.07.2020).

Редактор: Грицай Екатерина Анатольевна Переводчик: Бирюкова Полина Сергеевна 